\title{
0 conceito de pobreza: Uma reflexão sobre os interesses do conhecimento
}

\author{
The concept of poverty: A reflection on the interests of knowledge
}

\author{
Aline Accorssi ${ }^{[a]}$, Helena Beatriz Scarparo ${ }^{[b]}$, Pedrinho Arcides Guareschi ${ }^{[c]}$
}

\footnotetext{
${ }^{[a]}$ Psicóloga, doutoranda em Psicologia Social no Programa de Pós-Graduação em Psicologia da Pontifícia Universidade Católica do Rio Grande do Sul (PUCRS). Bolsista Capes, Porto Alegre, RS - Brasil, e-mail: alineaccorssi@gmail.com

${ }^{[b]}$ Psicóloga, doutora em Psicologia pela Pontifícia Universidade Católica do Rio Grande do Sul (PUCRS), professorapesquisadora no Programa de Pós-Graduação em Psicologia da Pontifícia Universidade Católica do Rio Grande do Sul (PUCRS), coordenadora do grupo de pesquisa Políticas Sociais e Psicologia: memória, história e produção do presente, Porto Alegre, RS - Brasil.

${ }^{[c]}$ Doutor em Psicologia Social University of Wisconsin at Madison, professor-pesquisador no Programa de Pós-Graduação em Psicologia Social e Institucional da Universidade Federal do Rio Grande do Sul (UFRGS), Porto Alegre, RS - Brasil.
}

\section{Resumo}

Este trabalho busca problematizar o papel do conhecimento no campo social por meio de uma reflexão sobre o uso do conceito de pobreza presente nos relatórios do Banco Mundial em uma perspectiva histórico-crítica. Levanta possíveis interpretações sobre quais são os interesses dessa instituição ao utilizar o conceito pobreza e ao divulgar as receitas direcionadas especialmente para os países em desenvolvimento no que se refere a como combatê-la. A partir dessa discussão ilustrativa, o artigo analisa o que pode estar por detrás da criação de um conceito e questiona-se sobre quais são os interesses do sujeito/pesquisador/instituição que articula as teorias.

Palavras-chave: Pobreza. Banco mundial. Neoliberalismo. Conhecimento.

\section{Abstract}

This study raises questions about the role of knowledge in the social field through a reflection on the use of the concept of "poverty" in the reports of World Bank in a historical-critical perspective. It also raises possible interpretations upon what are the interests of this institution when using the term poverty and disclosing revenue especially directed to developing countries with regards to the fight against this situation. Based on this illustrative discussion, this article analyses what there might be behind the creation of a concept and raises questions about what are the interests of the subject/researcher/institution that articulates those theories.

Keywords: Poverty. World Bank. Neo-liberalism. Knowledge. 


\section{Introdução}

O problema da pobreza no mundo não é novo. Se há algo novo, talvez seja a dimensão desse problema diante dos chamados avanços tecnológicos do último século e as suas possibilidades de mudança social. Mas, como podemos ter uma compreensão da dimensão desse problema, quando os dados divulgados são paradoxais?

Pesquisadores ligados à ONU advertem que em 2020, a pobreza urbana chegará a $45 \%$ ou $50 \%$ do total dos moradores das cidades (Davis, 2006). Por outro lado, os Indicadores do Desenvolvimento Mundial para 2007, produzidos pelo Banco Mundial (2008), apontam para a diminuição das taxas mundiais de pobreza nos quatro primeiros anos do século XXI. Como podemos confiar nos dados que as agências de pesquisa ou as agências de cooperação internacional divulgam? Será que o conceito de pobreza adotado é o mesmo? Será que os índices estão falando da mesma pobreza, das mesmas condições?

Perante essa problemática, o presente trabalho busca refletir sobre o papel do conhecimento no campo social a partir da análise de como o conceito de pobreza é adotado pelo Banco Mundial (BM) em seus relatórios. Em uma perspectiva histórico-crítica, levanta, também, possíveis compreensões sobre quais são as intenções dessa instituição, ao utilizar o conceito pobreza e ao divulgar as receitas direcionadas especialmente para os países em desenvolvimento no que se refere a como combatê-la. A partir dessa discussão ilustrativa, o artigo analisa o que pode estar por trás da criação de um conceito e questiona quem é o sujeito/ pesquisador/instituição que articula as teorias?

Para desenvolver tais reflexões, o artigo primeiramente apresenta uma contextualização do momento sócio-histórico em que o BM surge e se desenvolve; depois aborda a questão da luta contra a pobreza enquanto foco de intervenção dessa instituição e busca, nessa análise, interpretar os valores e princípios que podem estar dando um colorido especial às suas práticas. Por fim, discutem-se os interesses do conhecimento científico, bem como as implicações desses interesses para o desenvolvimento ou não da sociedade.

\section{Contextualização}

\section{0 ajuste neoliberal}

A partir da década de 1970, a chamada Era do Ouro, característica do período pós Segunda Guerra
Mundial, entrou em declínio. Quase todos os países desenvolvidos continuaram a crescer, mas num ritmo bem mais lento do que antes (Hobsbawm, 1995). Houve uma retração dos investimentos do setor produtivo, acompanhado de uma aceleração geral dos preços e endividamento dos governos, o que representou, tanto a falência do modelo fordista de acumulação capitalista, quanto a crise da ordem social do Welfare State (Ugá, 2004). A economia mundial ganhou uma outra configuração, principalmente com o fortalecimento dos mecanismos tecnológicos. Controle de documentos computadorizado, "melhores comunicações e transportes mais rápidos reduziram a importância do volátil 'ciclo de estoques' da velha produção em massa, que resultava em enormes estoques 'só para a eventualidade' de serem necessários em época de expansão" (Hobsbawm, 1995, p. 394), e depois parava subitamente quando os estoques eram liquidados em época de contração. Surge, então, um novo método de organização da produção capitalista, o toyotismo, que possibilitou ter estoques muito menores e a prover os vendedores just in time (na hora). Além disso, pôde desenvolver a capacidade de variar a produção repentinamente, a fim de enfrentar as exigências de mudança de um mundo cada vez mais instável. Os problemas sociais, tais como o desemprego em massa, a miséria, a instabilidade, dentre outros, que tinham dominado a crítica ao capitalismo antes da guerra, reapareceram no mesmo período (Hobsbawm, 1995).

Também, nesse momento, havia uma batalha entre keynesianos e neoliberais, uma guerra de ideologias que se incompatibilizavam, embora ambos os lados mostrassem argumentos de cunho econômico. Os primeiros diziam que altos salários, pleno emprego e o Estado de Bem-Estar Social haviam criado a demanda de consumo que alimentava a expansão e que, para sair da crise, o melhor seria incentivar a demanda na economia. Já os segundos afirmavam que a economia e a política da Era de Ouro impossibilitavam o controle da inflação. Somente com o corte dos custos no governo e na iniciativa privada poder-se-ia trazer de volta o aumento dos lucros que, segundo eles, seriam o verdadeiro motor do crescimento econômico de uma sociedade capitalista (Hobsbawm, 1995).

Foi nesse contexto que o neoliberalismo emergiu. Colocou-se como contraponto político, econômico e ideológico à predominância da intervenção 
estatal característica da Era de Ouro. Os dois países que lideraram a adoção desse modelo foram a Inglaterra em 1979, com a Margaret Thatcher, e os Estados Unidos em 1980, com Ronald Regan. A partir dessas experiências, houve um crescente processo de difusão do ideário neoliberal pelo mundo. Nos países desenvolvidos, as propostas neoliberais consistiram na redução do papel do Estado, no enfraquecimento dos sindicatos e na flexibilização do mercado de trabalho (Ugá, 2004). Contudo o ajuste neoliberal não foi conduzido da mesma forma em todos os países. Se nos países centrais, em que já havia um Estado de Bem-Estar Social estruturado e com recursos abundantes, o caráter recessivo das políticas de ajuste econômico provocou cortes lineares do gasto social e deterioração dos padrões do serviço público, na América Latina, em que o modelo de Welfare State nunca foi de fato uma realidade, o ajuste se deu pelo lado econômico, ou seja, abertura comercial, deslocalização de indústrias e atividades e desemprego (Soares, 2002).

Importante ressaltar que a Era do Ouro, para os países da América Latina, foi marcada pelo desenvolvimentismo (modelo que entrou em crise a partir da década de 1980). 0 processo de desenvolvimento econômico nesses países, nos anos de 1950 a 1960, se deu com o endividamento externo. O desenvolvimento econômico brasileiro, por exemplo, ocorreu em marcha forçada, ou seja, o governo optou por endividar-se para depois resolver o que faria com a dívida externa decorrente dessa escolha. A economia brasileira entrou em crise, conforme Ugá (2004, p. 56), com o segundo choque do petróleo em 1979, quando "houve um aumento da dívida externa em função do aumento das taxas de juro internacionais e uma drástica redução da entrada de recursos externos no país".

Na América Latina, os efeitos da crise financeira e a crise da dívida externa nos anos de 1980 levaram a um reforço do modelo que vinha sendo aplicado em alguns países desde meados da década anterior pelo Banco Mundial, o Fundo Monetário Internacional (FMI) e o governo dos Estados Unidos. Com a adoção de políticas liberalizantes, privatizantes e de mercado, buscava-se diminuir o déficit fiscal, reduzindo o gasto público. A exportação deveria ser o motor do crescimento, com a concentração do mercado privado, comprimindo cada vez mais a presença do setor estatal. 0 conceito que estava (e está) por detrás desses princípios é o livre jogo das forças de mercado.
Tal posicionamento mostra uma concepção de neutralidade, pois esses princípios poderiam ser difundidos e aplicados em qualquer lugar, independentemente do contexto (Soares, 2002).

Nos anos de 1980, principalmente a partir do Consenso de Washington, as ideias sobre as políticas de ajuste nas economias não industrializadas passaram a incorporar algumas dimensões de natureza corretiva. Uma delas é o próprio papel do Estado. Isso caracterizou o chamado paradoxo ortodoxo (Soares, 2002), ou seja, como conduzir uma transição que tinha no Estado o artífice da reforma principal: a reforma de si mesmo. Evoluiu-se, então, da ideia de minimização do Estado para a ideia de reconstrução. Independentemente do nome dado, fato é que esse foi um processo cheio de contradições. O capital internacional, conforme Costa (2006), buscou ampliar seu poder de mercado e manter a lucratividade dos investimentos a partir de uma ofensiva contra os salários, mas isso somente foi possível com algumas mudanças na legislação trabalhista, terceirizações e deslocamento de plantas produtivas. Para possibilitar o crescimento do poder de mercado das grandes empresas, os governos dos chamados países centrais pressionaram os países periféricos para que esses abrissem seus mercados e reduzissem os impostos sobre o capital.

O caráter desigual também foi nomeado de transformação produtiva sem equidade. Aliás, a marca global da modernização está dada pelo sentido comum de agravamento das desigualdades e da produção de exclusão. Esse tipo de transformação produtiva caracteriza-se por ser restrita e concentrada a partir das mudanças tecnológicas em poucos países, bem como numa distribuição desigual dos frutos do progresso técnico e dos custos sociais das políticas de ajuste e reestruturação. Os custos sociais têm sido pagos primordialmente pelos países periféricos, mas de modo geral, houve uma piora nos padrões de equidade social. Surgiu então de uma casta de rentistas, de bolsões de pobrezas e os desmontes dos mecanismos compensatórios do Welfare State, sobretudo em função da crise fiscal (Soares, 2002).

A agenda neoliberal focou suas reformas no corte dos gastos com os benefícios sociais, programas de privatizações, políticas voltadas para fortalecer o capital e desregulamentação do mercado de trabalho, com alterações nas leis trabalhistas e previdenciária. A globalização foi posta como fato irreversível, que 
exigia uma nova agenda para os Estados Nacionais, assim, inserir-se no processo da nova ordem mundial foi o desafio colocado pela ideologia neoliberal, a partir da década de 1980 (Costa, 2006).

Apesar de as evidências mostrarem que, ao menos na América Latina, os resultados da implantação das políticas consistiram no declínio das taxas de investimento e de crescimento, piora na distribuição de renda e aumento do desemprego (Ugá, 2004), a partir dos anos de 1980, o ideário neoliberal foi progressivamente ganhando espaço e legitimação. Ainda hoje representa uma importante força política presente nos debates públicos e espaços decisórios governamentais.

\section{Banco Mundial e suas recomendações}

O Banco Mundial, acompanhado do FMI, foi criado durante a conferência de Bretton Woods em 1944, proposta pelo governo norte-americano, com a intenção de traçar os contornos da nova ordem econômica que deveria ser instituída no pós-guerra. Ao mesmo tempo, estabeleceu-se um novo padrão monetário internacional, centrado no dólar com paridade fixa com o ouro (Mattos, 2001). O BM tinha como objetivo promover o investimento internacional e manter a estabilidade do câmbio, além de tratar de problemas de balanças de pagamento (Hobsbawm, 1995). As regras para o funcionamento do BM incluíram um dispositivo de captação de recursos junto aos mercados financeiros com as mais baixas taxas de mercado, destinados, evidentemente, para os países-membros (Misoczky, 2002). Também por proposição do governo norte-americano, após o fim da Segunda Guerra Mundial, foram criadas as instituições que compõem as Organizações das Nações Unidas para assegurar a segurança e a paz mundial (Mattos, 2001). Importante destacar que a criação destas organizações - as de Bretton Woods e as da ONU - são parte do plano político hegemônico mundial desenhado pelos Estados Unidos.

Entre 1974 e 1975, o FMI, seguido pelo BM, mudou o seu enfoque dos países industriais desenvolvidos para aqueles em desenvolvimento, que cambaleavam com o impacto dos preços cada vez mais altos do petróleo. Ao aumentar passo a passo os seus empréstimos, o FMI ampliou aos poucos o alcance das condicionalidades coercitivas e ajustes estruturais que impunha aos países seus clientes. Desde 1980, o Banco Mundial vem atuando como importante regulador e formulador de políticas para os países periféricos e, acompanhado do FMI, disseminador das políticas neoliberais (Ugá, 2004).

Como sabemos, o FMI, bem como outras agências internacionais de desenvolvimento, impõem condições para emprestar dinheiro determinando a reestruturação e ação de órgãos de governos municipais, estaduais e federais. Os empréstimos pagam consultores internacionais que, frequentemente, pouco conhecem da realidade local, mas conhecem muito bem os idênticos modelos que são impostos a diferentes países, de diferentes culturas, em diferentes cidades (Maricato, 2006) ${ }^{1}$.

A reforma do Estado, por exemplo, "estimulada pela ação do BM e do FMI, propõe como condição para o crescimento econômico e inserção na ordem mundial ajustes fiscais e estabilidade interna da moeda, o que torna necessário o controle dos gastos públicos e a geração de superávit primário nos países periféricos, para saldar juros da dívida externa" (Costa, 2006, p. 157). Em diferentes contextos, mas com consequências semelhantes, os Estados endividados passaram a depender do mercado financeiro. Com a mobilidade do capital ditando as regras, a autonomia na formulação da política econômica fica prejudicada e passa a ser cada vez mais difícil cobrar impostos num mundo globalizado. "A necessidade de criar postos de trabalho faz com que o capital tenha um poder de barganha muito grande sobre o governo, com um apelo ideológico repassado para a sociedade" (Costa, 2006, p. 164). E, quando o governo contraria as expectativas do capital, podemos assistir a um conjunto de manifestações midiáticas que afirmam e reafirmam a incompetência do Estado em gerir e manter os empregos em determinada região.

O BM passou a analisar a atuação dos governos também no âmbito social. Em consonância com os princípios neoliberais, prescreveu reformas especialmente nas áreas da educação e da saúde (alguns estudos, entre eles Ugá (2004), Misoczki (2002), Fonseca (1998), tomaram como foco de análise os relatórios do $\mathrm{BM}$ e, de certo modo, tentam

\footnotetext{
1 Em 2005, o Brasil pagou as dívidas com o Fundo e desligou-se da obrigatoriedade de seguir suas determinações. Apesar disso, alguns analistas afirmam que nada mudou, pois o Ministério da Fazenda mostrou-se menos flexível que o próprio FMI e fizeram superávits maiores do que aquele acordado com o Fundo, ou seja, 4,25\% (Maricato, 2006).
} 
compreender a ordem social que está por detrás de suas orientações). Além disso, após essas análises, o Banco constatou que as despesas governamentais com os serviços sociais não eram eficientes, pois não beneficiavam quem mais precisava delas: os pobres. Com tal conclusão, passou a recomendar fortemente que os países adotassem medidas focalizadas, ou seja, serviços sociais para as populações mais necessitadas. 0 tema da equidade foi colocado em pauta, frisando que a necessidade de intervenção deveria ser na educação primária e no atendimento preventivo na saúde, a atenção básica. "O ensino superior e $o$ atendimento hospitalar foram considerados secundários dentro das propostas de atuação do Estado na área social" (Costa, 2006, p. 209).

Sempre é importante lembrarmos que "a diminuição do tamanho do Estado não é um fator isento de interesses, mas evidencia a polêmica dentro da sociedade sobre que funções o Estado deve realizar e qual o seu papel na prestação de serviços sociais" (Costa, 2006, p. 208). No Brasil, essa problemática não surgiu dentro do governo Fernando Henrique Cardoso (FHC), mas foi incorporada por ele. A proposta de reduzir a intervenção estatal na área social foi difundida na década de 1990 pelos organismos internacionais, entre eles o $\mathrm{BM}$, muito embora o combate à pobreza seja a linha central de intervenção dessa instituição, como veremos a seguir.

\section{A "luta contra a pobreza": Algumas implicações}

Como já vimos, o modelo neoliberal é um modelo de acumulação que inclui por definição a informalidade no trabalho, o desemprego, o subemprego, a falta de proteção trabalhista e, como consequência, a produção de uma nova pobreza. Essas condições não são manifestações de que o sistema esteja funcionando mal, mas representa o funcionamento correto desse novo modelo de acumulação (Soares, 2002). E mais, o ajuste neoliberal não é apenas de natureza econômica: faz parte de uma redefinição global do campo político-institucional e das relações sociais. Os pobres passam a ser uma nova categoria classificatória, alvo das políticas focalizadas de assistência, mantendo a sua condição de pobre por uma lógica coerente com o individualismo que dá sustentação ideológica a esse modelo de acumulação (ganhadores e perdedores).

0 tema da pobreza é recorrente em grande parte dos relatórios apresentados pelos organismos internacionais, tais como: Banco Mundial, FMI e instituições das Nações Unidas. Contudo a sua constatação não significa necessariamente o reconhecimento das consequências de um modelo imposto pelas políticas neoliberais em todo o mundo (Soares, 2003). Ao invés de o Banco Mundial, por exemplo, recomendar estratégias para o enfrentamento dos elevados custos sociais decorrentes das políticas de ajuste, ou seja, propor soluções estruturais para o problema, o que ele tem feito foi centrar-se no combate da pobreza com políticas sociais focalizadas e compensatórias.

Para o BM, conforme já abordamos anteriormente, a universalização das políticas sociais foi considerada como um fator contrário à equidade, tendo em vista que beneficia setores da população que não estão dentro da linha da pobreza e que, portanto, podem pagar pelos serviços de educação e saúde. Apesar de tal argumento, no Brasil, por exemplo, tivemos algumas conquistas importantes quanto à universalização de políticas de saúde com o advento do SUS. Mas, certamente esse processo não foi e ainda não é tranquilo.

Segundo Costa (2006), as conquistas com a universalização do acesso sem melhorar a capacidade de investimento público na elevação da qualidade dos serviços ofertados para toda a população, fez a classe média buscar o mercado privado. Os usuários mais pobres, que foram inseridos no acesso aos serviços sociais, na medida em que não tinham esse acesso anteriormente, fizeram pouca pressão para elevar a qualidade do que estavam lhes oferecendo. "Reproduzindo a lógica da submissão, agradecem pelo fato de serem atendidos, sem considerar isso como um direito de cidadania" (Costa, 2006, p. 212). Na medida em que a classe média não reivindica o acesso pelos serviços públicos, que passam a serem vistos como de má qualidade, reforça-se a tese da equidade proposta pelo BM, de que o Estado deve atender exclusivamente os mais pobres.

Assim, em meio a tantas vozes sobre como ajudar os pobres a se ajudarem (exemplo disso é não dar o peixe, mas ensinar a pescar), pouca atenção se deu publicamente à importante redução dos direitos implícita na canonização pelo Banco Mundial. "Elogiar a práxis dos pobres tornou-se uma cortina de fumaça para revogar compromissos estatais históricos de reduzir a pobreza [...]" (Davis, 2006, p. 81).

É a partir da naturalização da pobreza e das desigualdades que o modelo devolve o conflito para 
o seio de uma sociedade fragmentada, na qual os atores se individualizam, ao mesmo tempo em que os sujeitos coletivos fragilizam suas identidades. "Muda, portanto, a orientação da política social: nem consumos coletivos nem direitos sociais, senão que assistência focalizada para aqueles com 'menor capacidade de pressão' ou os mais 'humildes' ou, ainda, os mais 'pobres'” (Soares, 2002, p. 73). Assim, o Estado neoliberal constrói uma faceta assistencialista como contrapartida de um mercado livre (acumulação), e o Banco Mundial pode se vangloriar de suas políticas com face humana, que ensinam a lutar contra a pobreza. Evidentemente esse processo traz consequências sérias para o cotidiano das comunidades: por um lado colabora com a naturalização do fenômeno da pobreza, garantindo a sua aceitação sem maiores questionamentos; e, por outro, o esvaziamento do conceito de cidadania social, ou seja, a garantia dos direitos sociais para muito além de meras políticas compensatórias (Ugá, 2004).

Davis (2006) ilustra a situação solidária do funcionamento do BM e, acrescentamos, do Estado neoliberal, como se fosse um apito de uma panela de pressão. Enquanto se desvia e se sublima a raiva política, garante-se que a situação não chegará ao ponto de explodir. A questão é: até quando isso se manterá?

\section{0 conhecimento científico e as práticas decorrentes}

Enquanto muitas pessoas, de um lado, são consideradas o alvo das políticas sociais, algumas outras, quase sempre de outro lado, trilham suas carreiras dentro do que se convencionou chamar de academia. Contudo para discutirmos a problemática do conhecimento científico e as práticas que dele decorrem, precisamos assumir de qual conceito de ciência estamos partindo. Nesse sentido, a filosofia da ciência pode contribuir para a discussão, uma vez que ela nos fornece vários modelos para a sua compreensão (Burawoy, 1990). Tomamos aqui as ideias propostas por Kuhn.

Thomas Kuhn foi um dos mais relevantes cientistas da contemporaneidade a considerar as influências históricas e sociológicas para a compreensão da produção do conhecimento, vinculando o desenvolvimento da ciência às práticas de grupos sociais. Renunciou ao conceito de teoria como unidade de análise da evolução da ciência, substituindo-o pelo de paradigma. Apesar de ter uma definição um tanto ambígua para esse termo (com 21 sentidos diferentes), de modo geral, faz referência a uma unidade de análise mais ampla que a teoria. Para o autor, paradigma é um conjunto de explicações teóricas sobre determinados fenômenos, provenientes de dados empíricos. E vai mais a fundo ao dizer que o conteúdo de determinado paradigma vai além do seu caráter científico; inclui, também, um significado sociológico, pois se refere ao desenvolvimento institucional que se produz em torno do paradigma dominante. Ou seja, o paradigma, inserido em uma rede de relações sociais, cria estruturas de poder para evitar que o desenvolvimento da atividade científica o ponha em risco (Álvaro \& Garrido, 2006).

Certamente, esse último aspecto, é o central para a nossa reflexão. Um paradigma ou um conjunto de explicações teóricas tem um significado sociológico, ou seja, para além do interesse acadêmico é possível identificar interesses institucionais na sua produção e perpetuação. Ao longo desse estudo, pudemos observar que o ator social analisado, o Banco Mundial, ainda representa os interesses hegemônicos de quem o criou, que, não por acaso, também é um dos países que liderou a implementação em escala mundial do neoliberalismo. Não caracterizamos isto como mera causalidade, ao contrário, insinuamos ao longo do debate que, ao tomar a categoria pobreza como foco de ação, o Banco Mundial, bem como seus financiadores, estão implementando em escala mundial um conjunto de valores e princípios calcados na concepção neoliberal. Ao mesmo tempo em que se cria necessidades com a política de ajustes, trabalha-se no sentido humanitário de reparo dos danos, com outras políticas focalizadas. Isso significa dizer que a dependência na figura do "bom amigo" é alimentada cotidianamente.

Outro aspecto relevante, conforme apontam Bauer, Gaskel e Allum (2002), é a discussão em torno dos interesses do conhecimento, pois a produção científica somente ocorre a partir deles. Podemos afirmar que ninguém consegue livrar-se dos interesses do conhecimento, apesar de alguns cientistas terem certeza da sua suposta neutralidade. Ao discutir essa questão, Habermas (Bauer, Gaskell \& Allum, 2002; Habermas, 2006) propôs uma tipologia de interesses do conhecimento a partir da análise de alguns autores. Para ele, existem três interesses constitutivos do conhecimento que estão na base das ciências empírico-analíticas, histórico-hermenêuticas e críticas. As ciências empírico-analíticas têm como base um interesse no 
controle técnico, ou seja, com o objetivo de obter o conhecimento científico adotam como imperativo racional o controle sobre as condições materiais em que nos encontramos e, a partir disso, buscam aumentar nossa saúde e segurança física e espiritual. As ciências empírico-analíticas promovem o estudo de leis que presidem os fenômenos naturais. Buscam a predição e a explicação dos fenômenos.

As ciências histórico-hermenêuticas têm um interesse no estabelecimento de consenso e, em função disto, tomam como imperativo a busca pela compreensão intersubjetiva que somente pode ser alcançada a partir da linguagem comum. A compreensão hermenêutica, que tem como finalidade restaurar canais rompidos de comunicação, trabalha com duas dimensões: 1) o elo entre a própria experiência de vida de alguém e a tradição à qual ele pertence; 2) a esfera da comunicação entre diferentes indivíduos, grupos e tradições. 0 cientista, em ambos os casos, procura aprender a língua que ele interpreta, mas deve aproximar-se da interpretação a partir de um ponto histórico específico. Ao fazer isso, o pesquisador leva em consideração a totalidade de interpretação que já está presente (uma vez que o próprio mundo social já é um mundo pré-interpretado) e entra no que se chama de círculo hermenêutico. É esse movimento que leva ao consenso entre os atores. Evidentemente que esse consenso jamais será absoluto, pelo contrário, ele é necessariamente fluido e dinâmico, pois ele é conseguido por meio de uma interpretação que evolui e continua a evoluir e modificar-se historicamente (Bauer, Gaskel \& Allum, 2002).

A ciência tem gastado muito tempo e energia com a descrição e brigas entre as metodologias. Parece ficar claro, inclusive, que o primeiro modelo encontra-se com muito mais frequência nas pesquisas quantitativas e o segundo nas pesquisas qualitativas. Contudo, ainda há um terceiro tipo de ciência e interesses, que dá um novo colorido a essa antiga discussão. Habermas aponta para um tipo de ciência crítica, que tem como interesse maior a emancipação. Sua principal tese é a de que os interesses emancipatórios fornecem o referencial para se avançar além do conhecimento nomológico e da compreensão hermenêutica, e nos permitem "determinar quando afirmações teóricas atingem regularidades invariantes da ação social como tal, e quando elas expressam relações ideologicamente congeladas de dependência que podem, em princípio, ser transformadas" (Bauer, Gaskel \& Allum, 2002, p. 33). É através de um processo autorreflexivo que as ciências críticas podem chegar a identificar estruturas condicionadoras de poder que, com o "uso de uma comunicação sistematicamente distorcida e de uma repressão sutilmente legitimada", tendem a se naturalizar na sociedade.

Sempre é importante lembrar que a pesquisa é uma prática social, produzida por atores e inserida em instituições. Se é uma prática, uma produção do pesquisador e das instituições, jamais poderemos adotar a postura de uma suposta neutralidade e imparcialidade em momento algum da pesquisa, inclusive ao decidir quem com ela se beneficiará.

\section{Considerações finais}

Ao longo dessa reflexão, não se teve como propósito responder a todos os questionamentos levantados, nem mesmo criminalizar certos atores sociais pelas práticas desenvolvidas. Buscou-se, a partir da problematização do papel do conhecimento, delinear e refletir como um conceito ou um construto pode ganhar vida e força no campo social.

Vimos que a categoria pobreza abordada pelo BM, estando no centro das discussões e das práticas contemporâneas, alimenta um conjunto de valores que acaba por naturalizar a desigualdade social e, ao mesmo tempo, a responsabilizar o sujeito pela melhoria de sua vida. Assim como, o cientista social, vinculado à academia ou a qualquer outra instituição, ao defender o seu campo teórico, também coloca uma série de condicionalidades que são, na verdade, os pressupostos delineadores de seu estudo e de sua prática.

Diante disso, surgem algumas questões que parecem centrais para o campo da epistemologia e das ciências sociais: Como os interesses do conhecimento alteram a compreensão e a própria realidade? E, mais, nessa configuração, todo conhecimento seria válido? 0 fato de se adotar teorias e paradigmas provenientes de outros países e continentes não distorcem o olhar e a produção de conhecimento? A nosso ver, a teoria produzida, bem como as questões que movem a produção, poderia estar contaminada de uma perspectiva e de interesses que não são os mesmos daqueles que a desfrutam. Permanece, portanto, a inquietação inicial: é de fato possível desvincular os interesses do conhecimento da produção do conhecimento? 


\section{Referências}

Álvaro, J. L., \& Garrido, A. (2006). Psicologia social: Perspectivas psicológicas e sociológicas. São Paulo: McGraw-Hill.

Banco Mundial. (2008). Site do Banco Mundial. Recuperado em 20 dez. 2008, em http://web.worldbank.org

Bauer, M., Gaskell, G., \& Allum, N. (2002). Qualidade, quantidade e interessses do conhecimento. Evitando confusões. In M. Bauer \& G. Gaskell. Pesquisa qualitativa com texto, imagem e som: Um manual prático (pp. 17-36). Petrópolis: Vozes.

Burawoy, M. (1990). O que nós entendemos por ciência? (P. Guareschi, Trad.). Revista America Sociological Review, 55, 775-793.

Costa, L. C. (2006). Os impasses do estado capitalista: Uma análise sobre a reforma do estado no Brasil. Ponta Grossa: UEPG; São Paulo: Cortez.

Davis, M. (2006). Planeta favela. São Paulo: Boitempo.

Fonseca, M. (1998). 0 banco mundial como referência para a justiça social no terceiro mundo: Evidências do caso brasileiro. Revista da Faculdade de Educação, 24(1). doi:10.1590/S0102-25551998000100004
Habermas, J. (2006). Técnica e ciência como ideologia. Portugal: Edições 70.

Hobsbawm, E. (1995). Era dos extremos: O breve século XX 1914-1991. São Paulo: Companhia das Letras.

Maricato, E. (2006). Posfácio. In M. Davis. Planeta favela. São Paulo: Boitempo.

Mattos, R. (2001). As agências internacionais e as políticas de saúde nos anos 1990: Um panorama geral da oferta de ideias. Ciência e Saúde Coletiva, 6(2), 377-389.

Misoczky, M. C. A. (2002). O Banco Mundial e a reconfiguração do campo das agências internacionais de saúde: Uma análise multiparadigmática. Anais do Encontro de Estudos Organizacionais: Observatório da Realidade Organizacional. Recife: PROPAD; UFPE; ANPAD.

Soares, L. T. (2002). Os custos sociais do ajuste neoliberal na América Latina. São Paulo: Cortez.

Soares, L. T. (2003). 0 desastre social. Rio de Janeiro: Record.

Ugá, V. D. (2004). A categoria "Pobreza" nas formulações de política social do Banco Mundial. Revista Sociologia Política, 23, 55-62. 